\title{
Simulation and Experimental Research on Nickel- based Coating Preparedby Jet Electrodeposition at Different Scanning Speeds
}

Fu xiuqing ( $\nabla$ fuxiuqing@njau.edu.cn )

College of Engineering, Nanjing Agricultural University

Jia Li

Nanjing Agricultural University

Hongwen Zhang

Nanjing Agricultural University

Jieyu Xian

Nanjing Agricultural University

\section{Research Article}

Keywords: jet electrodeposition, scanning speed, numerical calculation, experimental verification, characterization detection

Posted Date: July 13th, 2021

DOI: https://doi.org/10.21203/rs.3.rs-687389/v1

License: (9) This work is licensed under a Creative Commons Attribution 4.0 International License. Read Full License 


\title{
Simulation and Experimental Research on Nickel-based Coating Preparedby Jet Electrodeposition at Different Scanning Speeds
}

\author{
Xiuqing $\mathrm{Fu}^{1,2, *}$. Jia $\mathrm{Li}^{1} \cdot$ Hongwen Zhang ${ }^{3}$. Jieyu Xian ${ }^{1}$ \\ ${ }^{1}$ College of Engineering, Nanjing Agricultural University, Nanjing 210031, China \\ ${ }^{2}$ Key laboratory of Intelligence Agricultural Equipment of Jiangsu Province, Nanjing, 210031, China \\ ${ }^{3}$ School of Mechanical and Electrical Engineering, Shihezi University, Shihezi, 832003, China \\ *Correspondence: fuxiuqing@njau.edu.cn
}

\section{Abstract}

In order to study the processing mechanism of jet electrodeposition and explore the influence of different scanning speed on the wear and corrosion resistance of nickel-based coating prepared by jet electrodeposition. The reciprocating scanning motion of the nozzle was used to prepare the nickel-based coating in a specific area. Combined with COMSOL software, the coupling effect of multiple physical fields in the process of jet electrodeposition at different scanning speeds was numerically calculated. Scanning electron microscope, microhardness tester, material surface comprehensive performance tester and electrochemical workstation were used to analyze the surface morphology, section thickness, microhardness, abrasion resistance and corrosion resistance of the nickel-based coating prepared by jet electrodeposition at different scanning speeds. Results show that with the increase of scanning speed, coating grain size decreases, and the coating thickness increases after the first decreases, and microhardness increase after decreases first, abrasion resistance and corrosion resistance were lower after increase first, When the scanning speed reaches $600 \mathrm{~mm} / \mathrm{min}$, the jet electrodeposited nickel-based coating has the best performance, the maximum thickness reaches $24.83 \mu \mathrm{m}$, the microhardness reaches $616.86 \mathrm{HV}$, and the wear scar area is $2766.75 \mu \mathrm{m} 2$. In addition, the self-corrosion potential is $-0.33 \mathrm{~V}$, the self-corrosion current density is $5.16 \mathrm{E}-7 \mathrm{~A} \cdot \mathrm{cm} 2$, and the equivalent impedance is $4660 \Omega$. The experimental results are consistent with the simulation results, which verifies the accuracy of the simulation model and provides theoretical guidance for further experiments related to jet electrodeposition.

Keywords jet electrodeposition· scanning speed numerical calculation· experimental verification· characterization detection

\section{Introduction}

Electrodeposition method is a commonly used method to get different metals (such as copper, nickel, cadmium, zinc, etc.) ${ }^{[1-4]}$ and different coatings (such as alloy coatings, composite coatings $)^{[5-7]}$. The principle is simple: a voltage is applied between the cathode and the anode to produce a current, thus forming a metallic deposit on the surface of the cathode ${ }^{[8,9]}$. At present, the processing methods of jet electrodeposition are becoming more and more mature. The main focus of jet electrodeposition technology is on the composition of electroplating solution and the research of coating properties $^{[10,11]}$. In order to better understand the processing process of jet electrodeposition, people still have many difficulties to be solved, so the computer simulation is particularly important.

At present, the electrodeposition processing technology is becoming more and more mature. Due to the superiority and scientificity of simulation research, the research through software simulation has increasingly become the focus of scholars at home and abroad $^{[12,}$ 13]. Huang, $\mathrm{D}^{[14]}$ et al. established a mathematical model of the flow field of frictionassisted jet electrodeposition, simulated and explored the influence of the speed of the cathode surface on the deposition layer, and chose a better speed in the experiment to obtain a smooth and dense coating. When preparing Ni-SiC composites by jet electrodeposition method, Wei $\mathrm{Cui}^{[15]}$ et al. used ANSYS software to study the relationship between the jet velocity and kinetic energy of electroplating solution, and obtained the jet velocity corresponding to the maximum kinetic energy, which was used to test the performance of the coating. S. M. J. S. Shourije and M. E. Bahrololoom ${ }^{[16]}$ used COMSOL software to simulate the interference of electric field generated by 
obstacles of different types and sizes on electrodeposition. Through the study of current density and thickness of deposition layer. The results show that the electric field interference can reduce the thickness of the deposition layer, and the simulation results are in good agreement with the test results. Wang ${ }^{[17]}$ et al. used potentiostatic water bath jet electrodeposition process to prepare $\mathrm{Cu}-\mathrm{Zn}$ alloy microcolumn, and used simulation data of COMSOL software to describe the influence of field intensity on the composition and crystal phase of the alloy, as well as the growth rate and diameter of the microcolumn. However, the abovementioned researchers have not studied the numerical simulation calculation of jet electrodeposition under the joint action of multiple physical fields, nor have they carried out experiments to verify the forming law.

Based on this, this paper adopts the scanning jet electrodeposition method to prepare the $\mathrm{Ni}$ based coating on the surface of 45 steel matrix, combined with COMSOL Multiphysics ${ }^{\circledR}$ software to conduct numerical simulation and simulation calculation of the coupling effect of electric field, flow field, material transfer and temperature in the test process. Scanning electron microscope, microhardness tester, material surface comprehensive performance tester and electrochemical workstation were used to study the surface morphology, section thickness, microhardness, wear resistance and corrosion resistance of the nickel base coating prepared by jet electrodeposition at different scanning speeds. Through the comparison of simulation and experiment, the accuracy of the simulation model is verified and the optimal scanning speed of the prepared nickel base coating is determined.

\section{Scanning jet electrodeposition test principle}

The principle of jet electrodeposition is basically the same as that of ordinary electrodeposition, but the difference lies in the different mass transfer process of electroplating solution. The mass transfer form of ordinary electrodeposition is mainly diffusion and electromigration, while the main form of jet electrodeposition is convection, so jet electrodeposition speeds up the material transfer efficiency ${ }^{[18,19]}$. Jet electrodeposition technology is an outstanding representative in high-speed electroplating ${ }^{[20,21]}$. Due to its unique fluid dynamics characteristics, the surface of the cathode workpiece under the high-speed impact of electroplating solution is not only mechanically activated to effectively reduce the thickness of the surface layer and the diffusion layer at the negative workpiece, but also the metal grains are refined and the deposition layer is more compact. On the basis of jet electrodeposition, the nozzle is connected to the motion system. Under the control of the numerical control system, the nozzle moves over the workpiece with a fixed scanning speed to form a coating in the scanning area. In this experiment, jet electrodeposition was carried out on a self-built platform to prepare nickel-based coatings, and the scanning jet electrodeposition test platform is shown in Figure 1. 


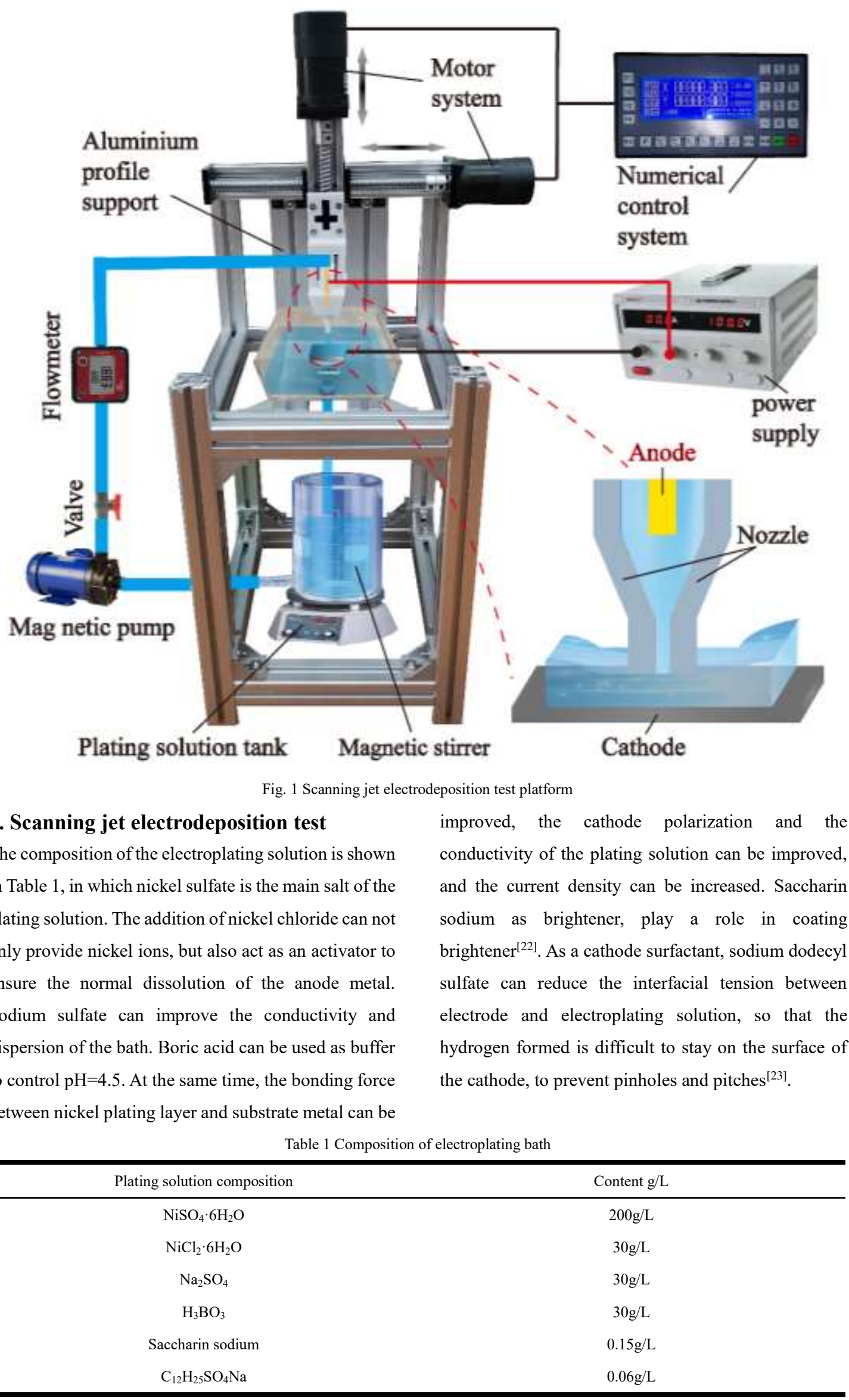


Before the test, the 45 steel sample should be pretreated, and its operation process is shown in Figure 2, including:45 steel wool embryo parts for sandpaper grinding and metallographic polishing cloth polishing treatment $\rightarrow$ Electric cleaning solution to remove oil, weak solution activation, strong solution activation $\rightarrow$ After ultrasonic cleaning, rinse with deionized water and dry.

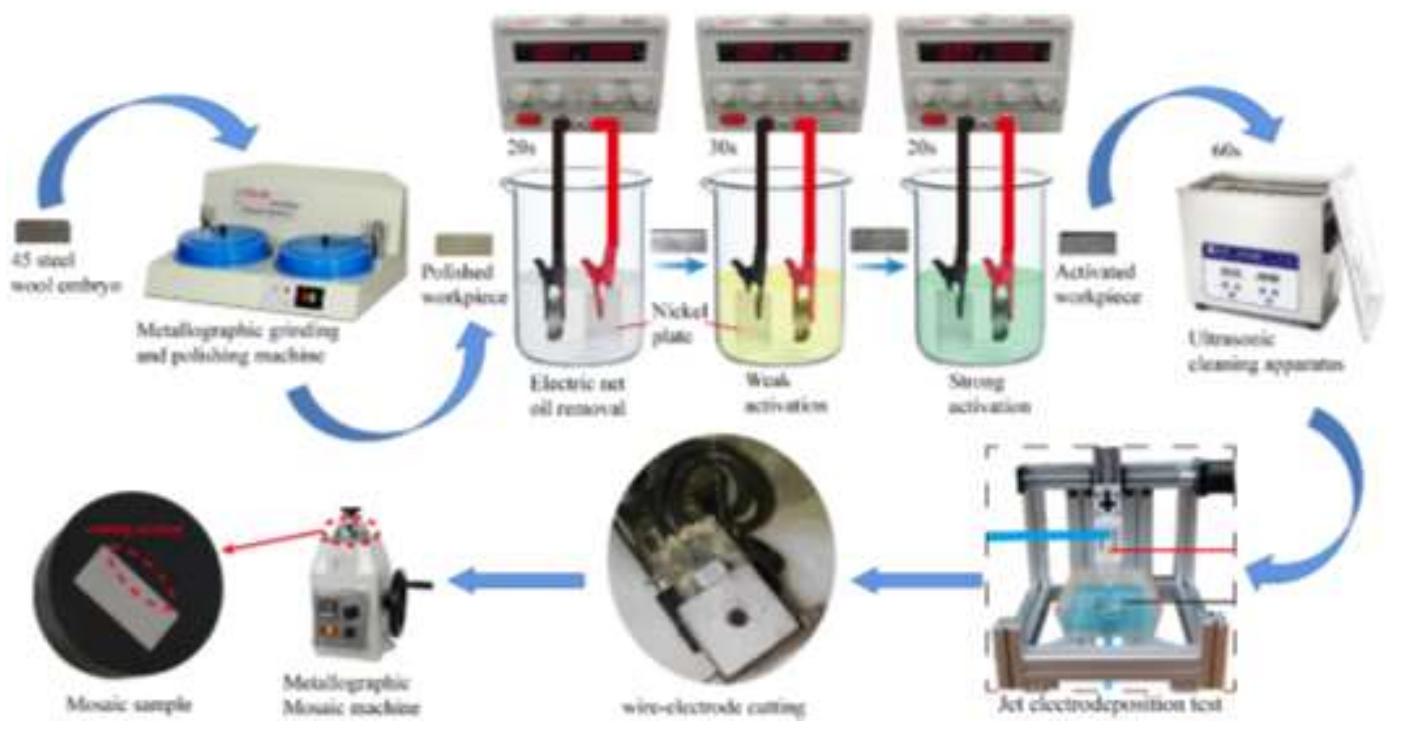

Fig. 2 Pre-treatment and post-treatment of the test

After the pretreatment, the jet electrodeposition test was carried out. Through the motion system and the control system, the anode nozzle was made to reciprocate at the speed of $200,400,600,800$ and $1000 \mathrm{~mm} / \mathrm{min}$. The specific test process parameters are shown in Table 2 . The reciprocating velocity of a single variable nozzle was controlled to study the influence of the reciprocating velocity on the growth of the electrodeposited nickel-based coating. After the test is completed, the 45-steel workpiece is cut into the coating along the direction of nozzle movement by wire cutting technology (as shown in Figure 2), and the coating cross section is obtained and then inlaid into the metallographic Mosaic machine to facilitate the thickness measurement of the coating cross section under the scanning electron microscope.

Table 2 Test process parameters

\begin{tabular}{cc}
\hline The process parameters & The numerical \\
\hline The solution temperature & $60^{\circ} \mathrm{C}$ \\
PH & $4.5 \pm 0.1$ \\
Current density & $5 \mathrm{~A} / \mathrm{dm}^{2}$ \\
Electroplating time & $10 \mathrm{~min}$ \\
Plating solution flow & $8 \mathrm{~L} / \mathrm{min}$ \\
Scanning speed & $200 、 400 、 600 、 800 、 1000 \mathrm{~mm} / \mathrm{min}$ \\
\hline
\end{tabular}

\section{Numerical analysis of COMSOL}

\subsection{Geometric model analysis}

According to the actual processing process and principle, the whole processing process basically remains unchanged along the direction perpendicular to the nozzle movement. Therefore, a simplified 2D model is adopted for simulation to establish the geometric model of scanning jet electrodeposition simulation as shown in Fig. 3, in which the whole geometric region is filled with electroplating solution. As shown in Fig. 2(b) $\Gamma 1$ boundary is the entrance of the plating solution into the nozzle cavity, the three edges indicated by section 2 are the metal anode boundary in the nozzle cavity, section 3 and section 4 are the plating solution outflow outlets, and pin 5 is the surface of cathode substrate. The remaining boundaries 
in Fig. 2(b) represent flux-free boundaries, in which the linear boundaries set by $\Gamma 6$ and $\Gamma 7$ contain a domain larger than the actual processing region. This modeling method can fully include the actual processing region, and the linear boundary is conducive to the calculation of the simulation model and can ensure the accuracy of calculation. Fig. 2(d), (e) and (f) respectively represent the geometric model distribution and mobile grid interface distribution of the electroplating bath simulation model in the software when the nozzles are at the leftmost end, the center position and the right end, respectively. The arbitrary Lagrangian - Eulerian (ALE) method to simulate dynamic grid reciprocating scanning movement, and considering the degree of movement influence on calculation convergence, a setting in the grid so easy to distortion auxiliary line (as shown in figure 2 local amplification figure), on the premise of keeping the continuity of physical fields, to the domain and the border of the grid division and refinement, so we can solve the problem of nonconvergence of calculation.

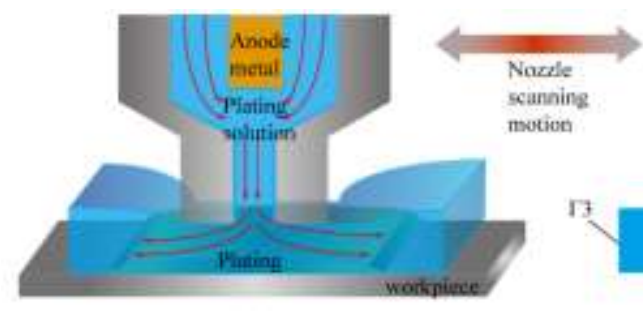

(a)

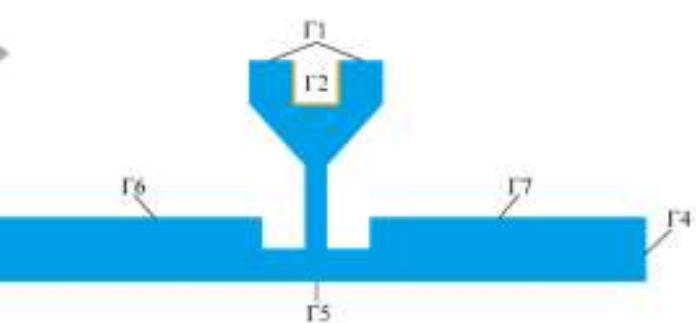

(b)

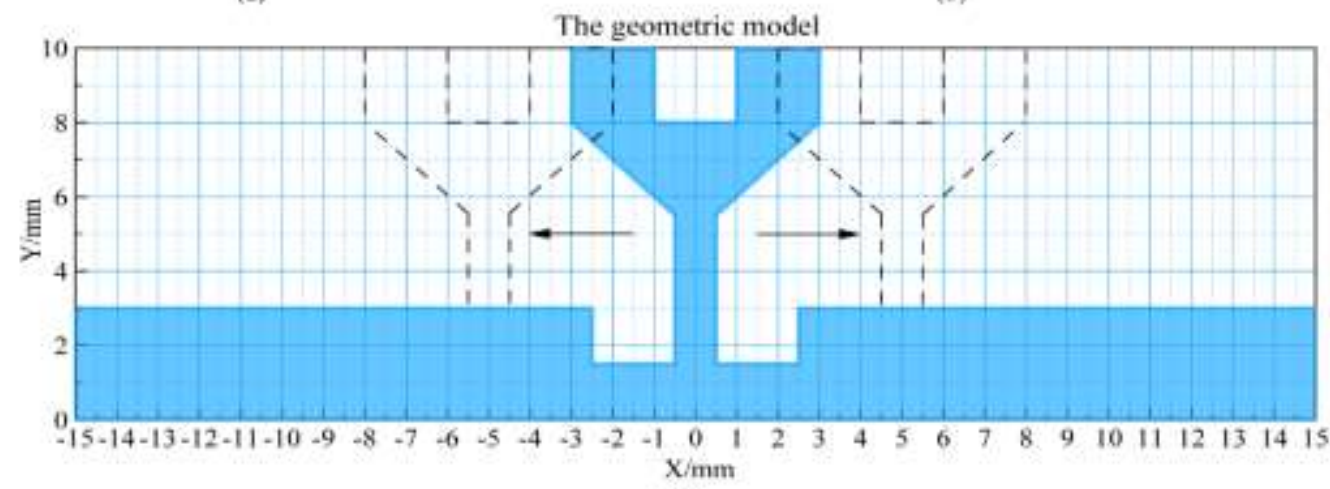

(c)

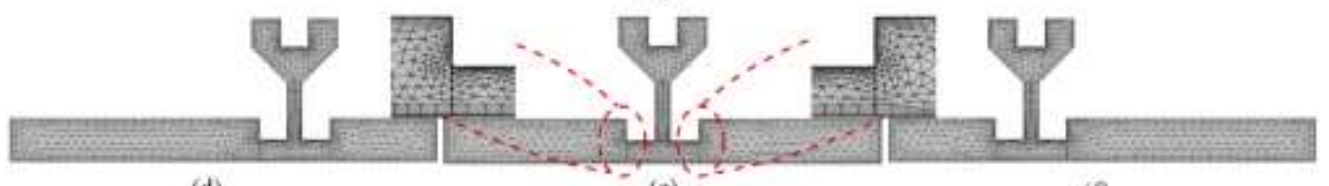

(d)

(c)

(f)

Fig. 3 Geometric model of simulation

\subsection{Mathematical model analysis}

The reaction rate and machining accuracy of jet electrodeposition are affected by many physical parameters, including flow field, electric field, material transfer-field and temperature field. The numerical theoretical model proposed in this paper is shown in Fig. 4.In this model, the mass transfer by convection and controlled by the flow field in electric field to control the effects of electric migration, and mass transfer reaction by influencing the electrolyte in the current density in electric field, temperature field affected by fluid heat transfer and electrochemical reaction boundary heat source, at the same time, through affect the conductivity of electrolyte, temperature changes and the current efficiency in the flow field and electric field. The following is the detailed analysis of the mathematical model: 


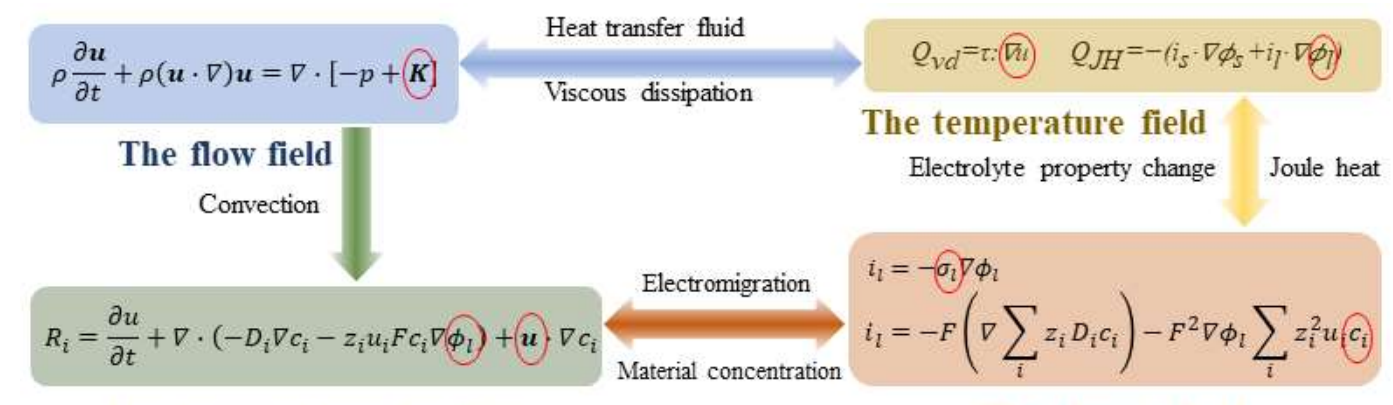

The material transfer field

The electric field

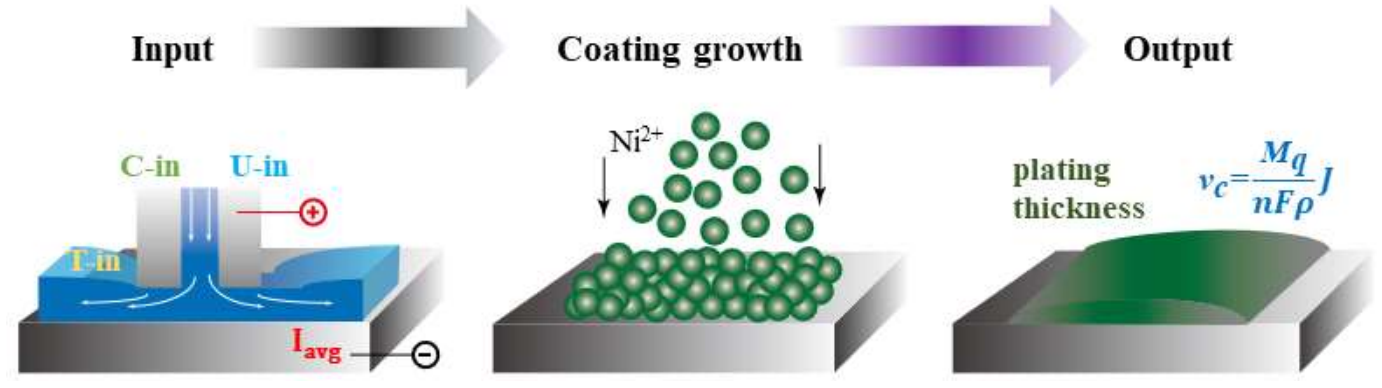

Fig. 4 Basic principle of mathematical model of jet electrodeposition

First in jet electrodeposition process, the electrolyte of high pressure and velocity, high flow rate to ensure the continuity and stability of the machining process, and complement the ions on the surface of the cathode consumption effectively, avoid the generation of concentration polarization. Critical Reynolds number is the criterion for judging liquid flow state, the pipeline flow of critical Reynolds number is about 2300, When the actual Reynolds number Re is less than the critical Reynolds number, it is laminar flow, and when it is greater than the critical Reynolds number, it is turbulent flow $^{[24]}$, the Reynolds number is defined by Eq. 1:

$$
R e=\frac{\rho v D}{\mu}
$$

Where $\rho$ represents the density of the plating solution, $\mathrm{v}$ represents the average velocity of the section inside the tube, D represents the hydraulic diameter of the section of the flow (the diameter in the water is four times of the radius of the water, the radius of the water is equal to the ratio of the effective wetting area and the wetting perimeter of the liquid flow), $\mu$ represents the dynamic viscosity of the fluid. For the nozzle inlet, $\rho=1290.21 \mathrm{~kg} / \mathrm{m}^{3}, \mathrm{D}=0.006 \mathrm{~m}, \mu=0.001798 \mathrm{~Pa} \cdot \mathrm{s}$. When $\mathrm{v}$ is greater than $0.53 \mathrm{~m} / \mathrm{s}$, the flow in the nozzle cavity is turbulent. In order to simplify the calculation, the following assumptions are made for the fluid during the modeling: (1) the electrolyte is a continuous incompressible viscous fluid, and the electrolyte is in an ideal state without impurities such as bubbles and solid particles ${ }^{[25]}$; (2) Mass transfer is the result of diffusion, diffusion is a constant at a given temperature, convection is determined by the flow field and the migration driven by the electric field, and the whole process satisfies the mass conservation equation and momentum conservation equation ${ }^{[26]}$. Based on the above analysis and reasonable assumptions, the electroplating liquid flow field is controlled by the k- $\varepsilon$ equation of the Reynolds mean (RANS) type in the incompressible fluid turbulence model, as shown in Eq. 2:

$$
\left\{\begin{array}{c}
\rho \frac{\partial \boldsymbol{u}}{\partial t}+\rho(\boldsymbol{u} \cdot \nabla) \boldsymbol{u}=\nabla \cdot[-p+\boldsymbol{K}]+\boldsymbol{F} \\
\frac{\partial \rho}{\partial t}+\rho \nabla \cdot \boldsymbol{u}=0 \\
\boldsymbol{K}=\left(\mu+\mu_{T}\right)\left(\nabla u+(\nabla u)^{T}\right)
\end{array}\right.
$$

Where $\rho$ represents fluid density, $\mathrm{F}$ represents the volume force (only gravity in this model, $\mathrm{F}=\rho \mathrm{g}$ ), $\mathrm{P}$ represents static pressure, $\nabla$ is the Laplacian formula. The boundary conditions are as follows: the inlet boundary conditions of the flow field are set as the constant normal inflow velocity $\mathrm{u}=\mathrm{u}$-in, and the outlet boundary conditions are set as the pressure $\mathrm{P}_{0}=0 \mathrm{~Pa}$. The inner and outer surfaces of the nozzle and the cathode surface are all set as "wall and no slip", and the influence of wall surface roughness on electrolyte flow 
is also ignored.

In the process of jet electrodeposition, the concentration of the electrolyte is mainly affected by the reaction between the flow field and the electrode, and the change of the concentration will lead to the change of the reaction current density, that is, the material transfer process and the electrode reaction process influence each other, and the material transfer process is also affected by the flow field. The expression of the material transfer model is expressed in Eqs. 3 and 4:

$$
\begin{gathered}
R_{i}=\frac{\partial u}{\partial t}+\nabla \cdot\left(-D_{i} \nabla c_{i}-z_{i} u_{i} F c_{i} \nabla \phi_{l}\right)+\boldsymbol{u} \cdot \nabla c_{i} \\
\frac{\partial c_{i}}{\partial t}+u \frac{\partial c_{i}}{\partial x}+v \frac{\partial c_{i}}{\partial y}+w \frac{\partial c_{i}}{\partial z}=D \nabla c_{i}
\end{gathered}
$$

Where $R_{i}$ represents the total molar flux of substance $i$, $D_{i}$ represents the diffusion coefficient, $c_{i}$ represents the concentration of ion $i, z_{i}$ represents the number of charges, $u_{i}$ represents mobility $(\mathrm{s} \cdot \mathrm{mol} / \mathrm{kg}), \mathrm{F}$ represents Faraday constant, and the value is $9.65 \times 10000 \mathrm{C} / \mathrm{mol}, \mathrm{u}$ stands for the velocity vector $(\mathrm{m} / \mathrm{s})$.

In addition, the "secondary current distribution" model is used to explain the distribution law of electric field. In the numerical simulation of jet electrodeposition, the potential and current density in the electrode and electrolyte must be solved respectively, and at the same time, the substance concentration in the whole process and the electrochemical reaction involved must be considered. Electrodes in electrochemistry are usually metal conductors, so their current-current relationship follows Ohm's law and the current conservation formula, which is represented by Eq. 5:

$$
\left\{\begin{array}{c}
i_{s}=-\sigma_{s} \nabla \phi_{s} \\
\nabla \cdot i_{s}=Q_{s}
\end{array}\right.
$$

A similar system of equations also exists in the electrolyte, represented by Eq. 6 :

$$
\left\{\begin{array}{c}
i_{l}=-\sigma_{l} \nabla \phi_{l} \\
\nabla \cdot i_{l}=Q_{l}
\end{array}\right.
$$

Where $i_{s}$ and $i_{l}$ represent the current density vector $\left(\mathrm{A} / \mathrm{m}^{2}\right)$ in the electrode and electrolyte, $\sigma_{s}$ and $\sigma_{l}$ respectively represent the conductivity of the metal electrode and electrolyte $(\mathrm{S} / \mathrm{m}), \phi_{s}$ and $\phi_{l}$ represent the electrode potential and electrolyte potential (V), $Q_{s}$ and
$Q_{l}$ represent the general current source term $\left(\mathrm{A} / \mathrm{m}^{3}\right.$, usually zero). At the same time, the electrolyte is an ionic conductor, and its net current density can be described by the sum of the fluxes of all ions, which satisfies Eq. 7:

$$
\boldsymbol{i}_{\boldsymbol{l}}=F \sum z_{i} N_{i}
$$

Where $i_{l}$ represents the current density vector $\left(\mathrm{A} / \mathrm{m}^{2}\right)$ of the electrolyte; $N_{i}$ represents the flux of substance $i$ $\left(\mathrm{mol} /\left(\mathrm{m}^{2} \cdot \mathrm{s}\right)\right) ; z_{i}$ is the charge of the substance. The ion flux in an ideal electrolyte solution can be described by the Nernst-Planck equation, which explains the flux of solute substances through diffusion, migration, and convection (respectively corresponding to the three terms on the right side of the formula), as shown in Eq. 8:

$$
N_{i}=-D_{i} \nabla c_{i}-z_{i} u_{i} F c_{i} \nabla \phi+\boldsymbol{u} c_{i}
$$

In addition to the conservation of current in the electrode and electrolyte, the current at the interface must also be conserved. The electroplating solution with a high concentration of metal ions is sprayed onto the cathode workpiece at a high speed, so that the concentration of metal ions near the cathode does not decrease, that is, the current density is limited by the mass transfer of electroactive substances, but the electrolyte composition is basically unchanged, so it is not necessary to solve the complete cubic current distribution. At the same time, the ionic strength is basically unchanged. It can be assumed that the electrolyte solution obeys Ohm's law and has a constant conductivity. Therefore, the electrolyte potential can be solved by using the secondary current distribution. The electrode-electrolyte surface dynamics equation selects the Butler-Volmer equation, which is shown by Eqs. 9, 10 , and 11 :

$$
\begin{gathered}
I=I_{0}\left(e^{\frac{\alpha_{a} F \eta}{R T}}-e^{\frac{\alpha_{c} F \eta}{R T}}\right) \\
\eta=\phi_{s}-\phi_{l}-E_{e q} \\
E_{e q}=E_{0, e q}+\frac{d E_{e q}}{d T}\left(T-T_{r e f}\right)
\end{gathered}
$$

Where $I$ represents the current density on the electrode surface, $I_{0}$ represents the exchange current density, $\alpha_{a}$ represents the anode transfer coefficient, $\alpha_{c}$ represents the cathodic transfer coefficient, $\mathrm{R}$ represents the ideal 
gas molar constant, $\mathrm{T}$ is thermodynamic temperature; $\eta$ means overpotential, $E_{\text {eq }}$ represents equilibrium potential, $\mathrm{E}_{0 \text {, eq }}$ is the standard equilibrium potential; $\mathrm{T}_{\text {ref }}$ represents the reference temperature, set as $293.15 \mathrm{~K}$.

In the process of numerical calculation, the metal ions on the surface of the cathode undergo reduction reaction, which leads to the change of cathode boundary, that is, cathode growth. According to Faraday's law, the cathode growth process is represented by Eqs. 12 and 13:

$$
\begin{gathered}
M=K Q=K I t \\
K=\frac{M_{q}}{n F}
\end{gathered}
$$

Where $\mathrm{M}$ represents the mass of precipitated metal, $\mathrm{K}$ represents the proportionality constant (electrochemical equivalent), Q represents the amount of electricity passing through, $\mathrm{T}$ represents the power on time, $\mathrm{M}_{\mathrm{q}}$ represents the molar mass of a substance, $\mathrm{n}$ represents the absolute value of the total number of positive or negative valence in the compound. The relationship between the deposition rate and the current density on the electrode surface is expressed by Eq. 14:

$$
v_{c}=\eta \frac{M_{q}}{n F \rho} I
$$

Where $\rho$ denotes the density of the precipitated metal, $\eta$ denotes the processing efficiency, which is $100 \%$ in the simulation calculation.

Finally, accompanied by heat transfer and temperature change in the process of jet electrodeposition, heat source in the processing process includes the charge transport in the electrolyte and the charge transport in the electrode material produced by the Joule heat, the heat generated in the electrode reaction, these make the electroplating solution in the process of flowing with heat to produce temperature changes, thus affecting the current efficiency and the conductivity of the electrolyte. Wherein, the Joule heat generated in the electrode and the electrolyte and the heat generated by the electrochemical reaction are represented by Eqs. 15 and 16, respectively:

$$
\begin{gathered}
Q_{J H}=-\left(i_{s} \cdot \nabla \Phi_{s}+i_{l} \cdot \nabla \Phi_{l}\right) \\
Q_{m}=J\left(\eta+T \frac{\partial E_{e q}}{\partial T}\right)
\end{gathered}
$$

Eq. 17 is the general equation of fluid heat transfer theory:

$$
\begin{aligned}
\rho C_{p}\left(\frac{\partial T}{\partial t}+u \cdot \nabla T\right) & +\nabla \cdot\left(q+q_{r}\right) \\
& =\alpha_{p} T\left(\frac{\partial p}{\partial t}+u \cdot \nabla p\right)+\tau: \nabla u \\
& +Q
\end{aligned}
$$

Where $\rho$ denotes the density of electroplating solution $\left(\mathrm{kg} / \mathrm{m}^{3}\right), C_{p}$ represents the specific heat capacity of the electroplating solution $(\mathrm{J} / \mathrm{kg} \cdot \mathrm{K})$, $\mathrm{T}$ denotes the absolute temperature $(\mathrm{K}), \mathrm{u}$ denotes the plating liquid velocity vector $(\mathrm{m} / \mathrm{s}), q$ represents conduction heat flow $\left(\mathrm{W} / \mathrm{m}^{2}\right)$, $q_{r}$ represents radiant heat flow $\left(\mathrm{W} / \mathrm{m}^{2}\right), \alpha_{p}$ represents the coefficient of thermal expansion $(1 / \mathrm{K}), p$ stands for pressure $(\mathrm{Pa}), \tau$ stands for the viscous stress tensor $(\mathrm{Pa})$, $\mathrm{Q}$ represents the heat source $\left(\mathrm{W} / \mathrm{m}^{3}\right)$ except viscous dissipation. Whereinto, the first term on the right side of the equation is the work done by pressure change, which is the result of heating under adiabatic compression, and the second term is the heat generated by viscous dissipation in the fluid. They are represented by Eqs. 18 and 19, respectively:

$$
\begin{gathered}
Q_{p}=\alpha_{p} T\left(\frac{\partial p}{\partial t}+u \cdot \nabla p\right) \\
Q_{v d}=\tau: \nabla u
\end{gathered}
$$

In this model, $q=-k \nabla T, q_{r}=0, Q=Q_{J H}+Q_{m}$, therefore, Equation 20 corresponds to the temperature field equation of this model:

$$
\rho C_{p}\left(\frac{\partial T}{\partial t}+u \cdot \nabla T\right)+\nabla \cdot(-k \nabla T)=Q_{p}+Q_{v d}+Q
$$

Where $\mathrm{k}$ represents the heat transfer coefficient of the electroplating solution.

\subsection{Analysis of numerical calculation results}

\subsubsection{Multi-physical field distribution results}

As the coordinate $\mathrm{X}$ of the center line of the nozzle changes, the distribution of the physical field also changes with time. The flow field distribution at different positions of the nozzle in the last scanning period is intercepted. It can be seen from Fig. 5 that the velocity of the flow field increases with the increase of the scanning velocity of the nozzle. The direction and magnitude of the electrolyte flow velocity on the surface of the cathode workpiece are constantly changing due to the reciprocating scanning motion of 
the nozzle. This is conducive to the uniform diffusion of metal ions and heat in the deposition process, which is conducive to the uniform growth of the coating. Driven by the nozzle, the scanning jet electrodeposition minimizes the existence of eddy currents and stagnant water areas, which is conducive to heat and material transfer, thus making the conductivity of the electrolyte and the concentration distribution of metal ions in the electrochemical reaction uniform and efficient. Through the simulation analysis of the flow field distribution, it is known that the flow lines do not interfere with each other in the process of electroplating liquid flow, and the material transport determined by the convection term only travels along the flow line direction.

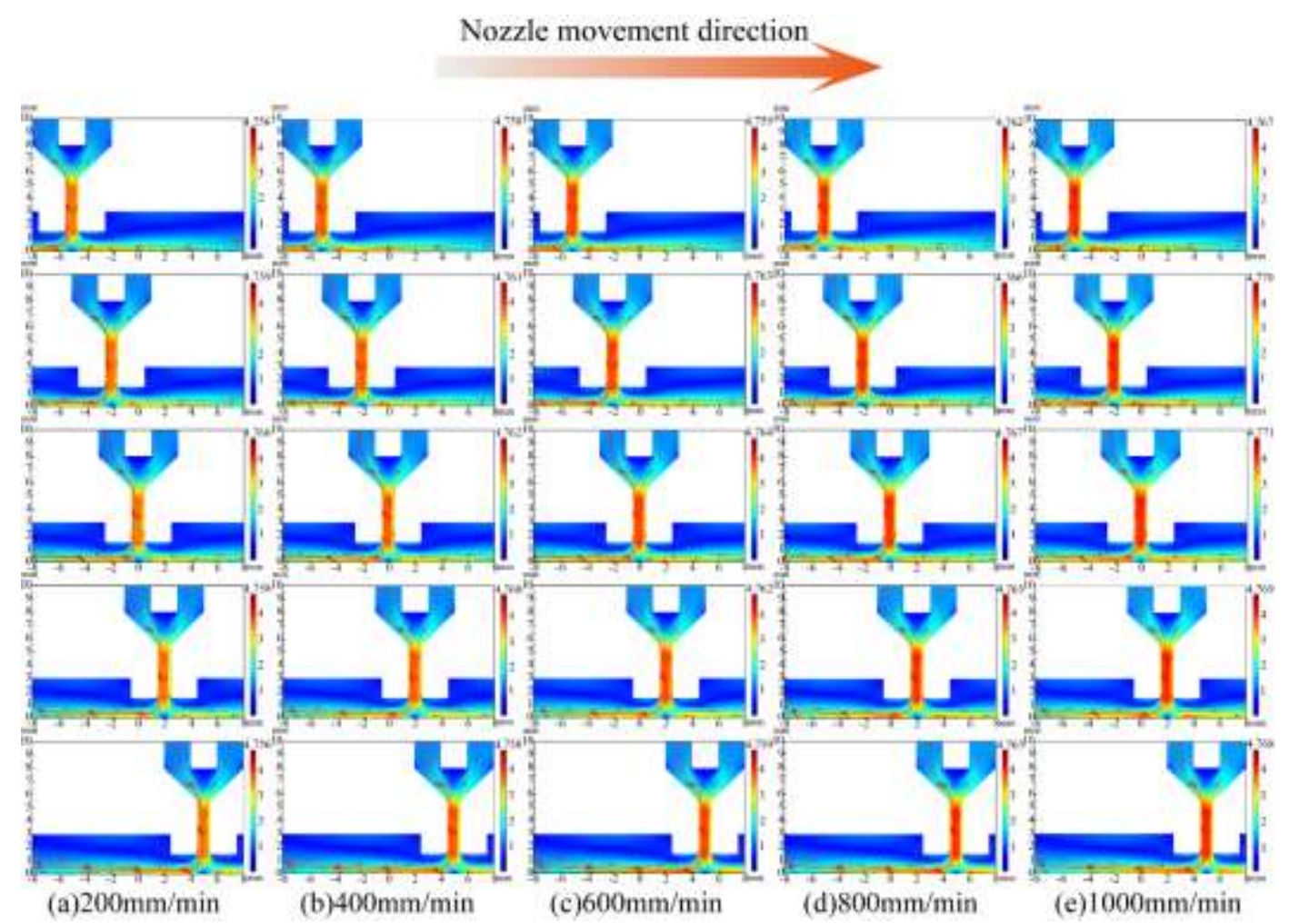

Fig. 5 Velocity of flow field at different positions

Figure 6 is the location of different electrolyte and electrode current density size when the size distribution, surface current density is known as geometric constraints, near the mouth of the nozzle inner cavity of the highest current density, electrolyte with movement of the nozzle from the left to the right, the current density value increases after the first decreases, and when the nozzle in the center position, namely the $\mathrm{X}=0$, electrode surface current density is the largest, This also results in the formation of a coating with a higher central thickness than the two sides. Under the coupling action of multiple physical fields, the peak value of current density decreases with the increase of scanning speed, and the peak value of electrolyte current density at the scanning speed of $200 \mathrm{~mm} / \mathrm{min}$, $400 \mathrm{~mm} / \mathrm{min}$ and $600 \mathrm{~mm} / \mathrm{min}$ is close to that at the scanning speed of $800 \mathrm{~mm} / \mathrm{min}$ and $1000 \mathrm{~mm} / \mathrm{min}$, which is greatly different from that at the scanning speed of $800 \mathrm{~mm} / \mathrm{min}$ and $1000 \mathrm{~mm} / \mathrm{min}$. 


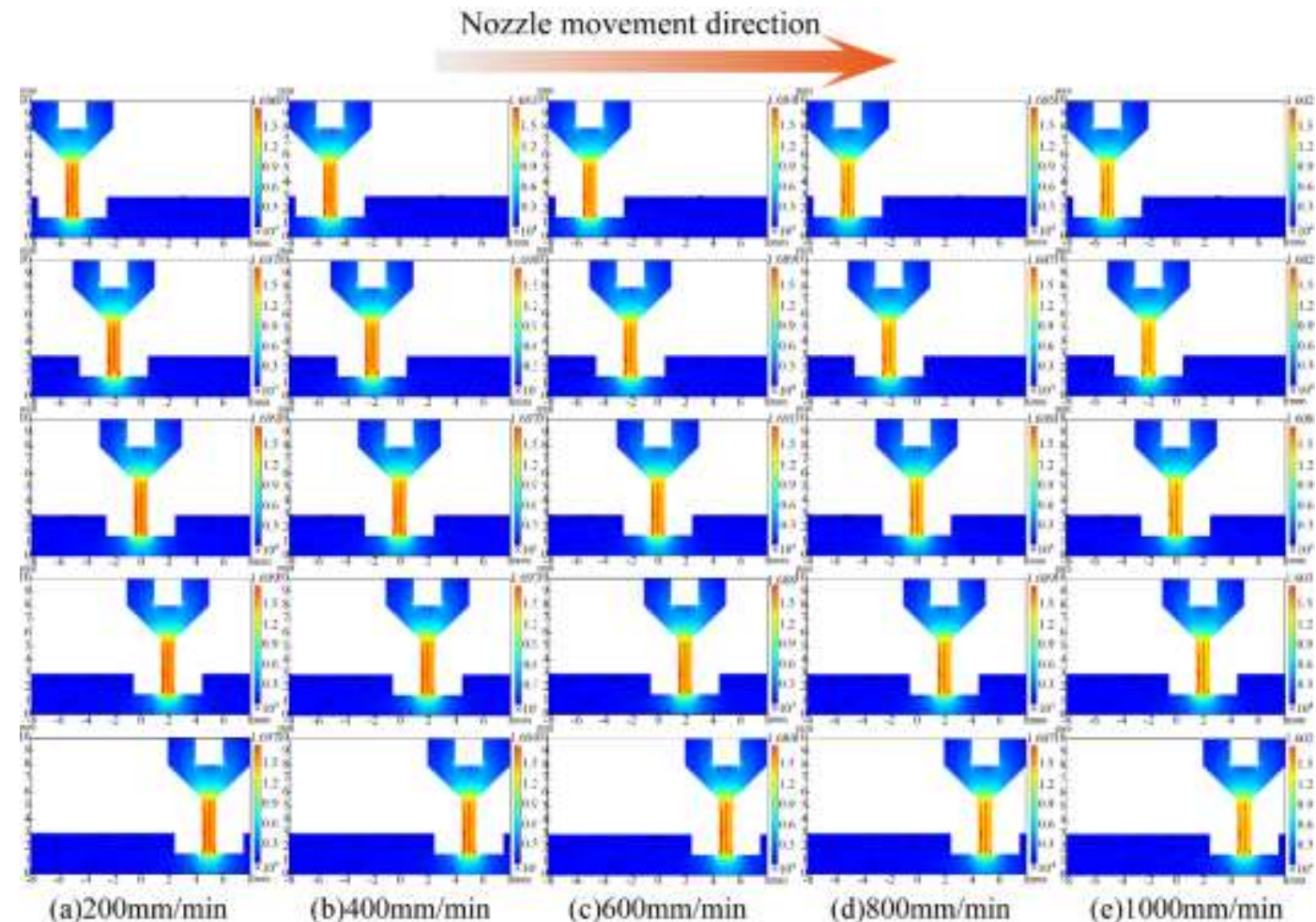

Fig. 6 Current densities of electrolyte and electrode surface at different positions

Fig. 7 shows the size and distribution of electrolyte concentration in the processing area at different positions. The size and distribution of the electrolyte concentration in the electroplating solution are affected by the combined action of the flow field and the electric field. The electrolyte moves through the nozzle to the cathode workpiece. The electrolyte concentration is the lowest at the electrode surface directly below the nozzle. This is due to the electrode reaction occurring at the position where the nozzle passes, the electrolyte concentration in the electroplating solution is consumed a lot, and at the same time, the unreacted electrolyte moves to both sides due to the effect of the jet of fluid. When the scanning speed is $600 \mathrm{~mm} / \mathrm{min}$, the electrolyte concentration on both sides is the highest, and the concentration in the center is the lowest, indicating that the electrodeposition reaction is the fastest at $600 \mathrm{~mm} / \mathrm{min}$. 


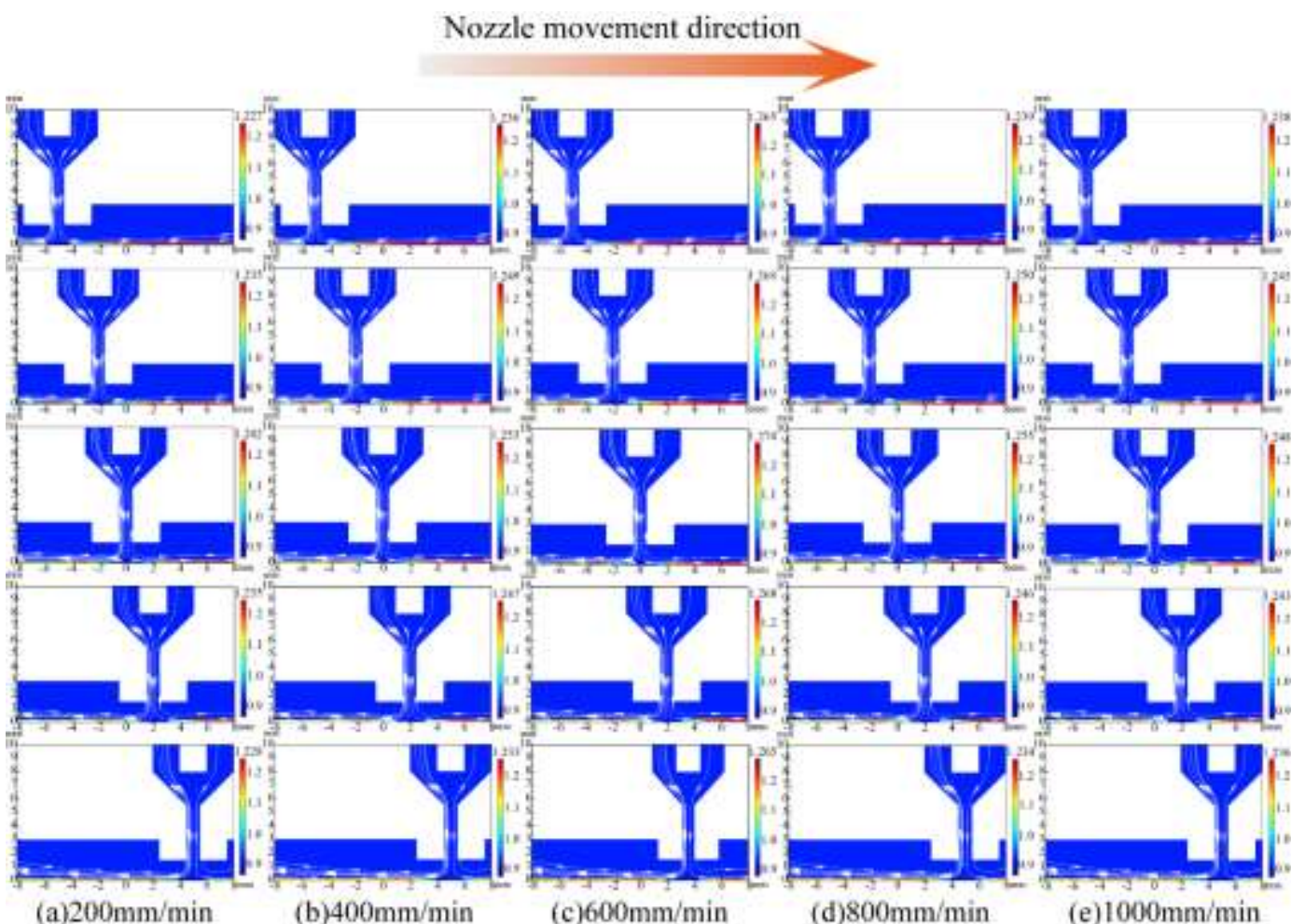

Fig. 7 Size and distribution of electrolyte concentration at different locations

\subsubsection{Coating thickness distribution results}

Fig. 8 shows that the growth thickness of the coating changes with the change of the scanning speed of the nozzle. Within a certain range, with the increase of the scanning speed, the maximum thickness of the coating first increases and then decreases. When the scanning speed is $600 \mathrm{~mm} / \mathrm{min}$, the maximum coating thickness is obtained. With the increase of scanning speed, the flatness of the coating gradually decreases. This is because the larger the scanning speed, the faster the material diffuses to both ends, resulting in insufficient deposition. As a result, the thickness of the coating decreases faster from the center to both en

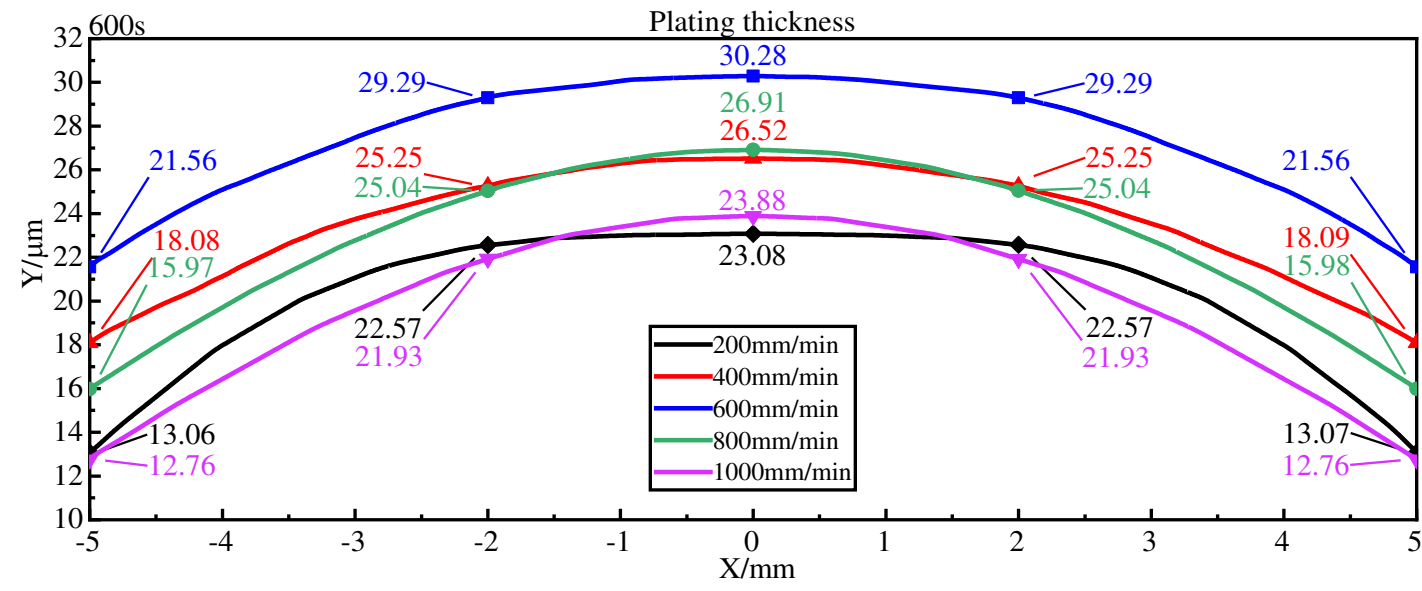

Fig. 8 Coating thickness at different scanning speeds

\section{Comparison and analysis of test results and simulation results}

The scanning speed of the nozzle has two main effects on the jet electrodeposition. First, the scouring effect caused by the movement of the nozzle will affect the growth of the coating. Meanwhile, the speed of the scanning movement of the nozzle will affect the deposition amount of each position of the coating. The surface morphology and section thickness of the coating were observed by FEI-SEM, Quanta FEG250 
scanning electron microscope (FEI Instruments, Oregon, USA).The surface morphology of the coating center at different scanning speeds is shown in Fig. 9. As can be seen from the figure, when the scanning speed is $200 \mathrm{~mm} / \mathrm{min}$, the surface of the deposition layer presents an obvious large-size cellular structure with clear and distinct boundaries, and the surface of the coating is obviously uneven. When the scanning speed of the nozzle increases to $400 \mathrm{~mm} / \mathrm{min}$, the grain size decreases obviously; when the scanning speed is $600 \mathrm{~mm} / \mathrm{min}$, the grain size on the surface of the deposition layer continues to decrease, and the surface is smooth and compact. When the nozzle scanning speed continues to increase to $800 \mathrm{~mm} / \mathrm{min}$ and $1000 \mathrm{~mm} / \mathrm{min}$, the grain size is basically the same as that of $600 \mathrm{~mm} / \mathrm{min}$, indicating that the continued increase of scanning speed has limited influence on the grain size of the coating, and at this time, the surface of the deposition layer appears fine chip, crack, holes and other defects.

The reason is that when the scanning speed is small, the current action time in the area just below the nozzle is long, and the grains can fully grow, so the grain size is large. With the increase of scanning speed, nozzle directly by the regional electric time is shorter, not fully deposition substrate metal ions, so the formation of the grain size is relatively small, while at the same time with the increase of number of scanning area lead nozzle directly can form more grain, thus increasing scanning speed to the grain refinement. However, when the scanning speed is too high, the change of force on the flow field in the working area is intensified, leading to obvious disorder of the flow field, and the stability of the fluid passing through the surface of the substrate is reduced. Furthermore, various defects are formed on the coating surface when the scanning speed is too high. Therefore, proper scanning speed is beneficial to obtain better sediment quality.

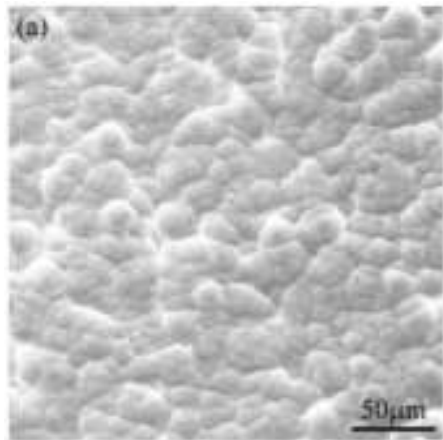

(a) $200 \mathrm{~mm} / \mathrm{min}$

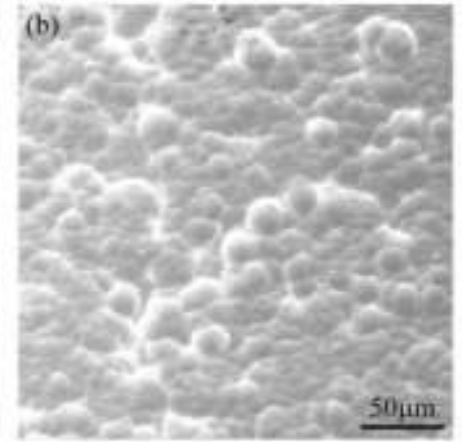

(b) $400 \mathrm{~mm} / \mathrm{min}$

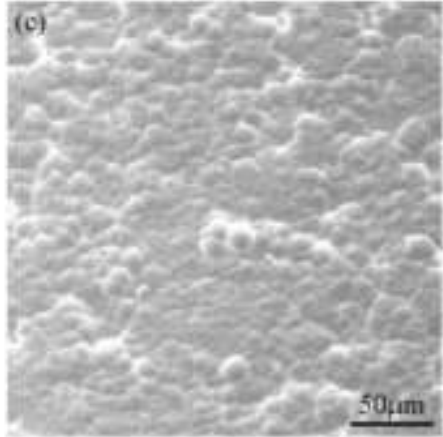

(c) $600 \mathrm{~mm} / \mathrm{min}$

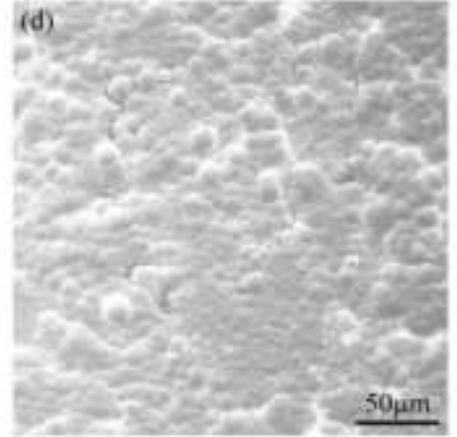

(d) $200 \mathrm{~mm} / \mathrm{min}$

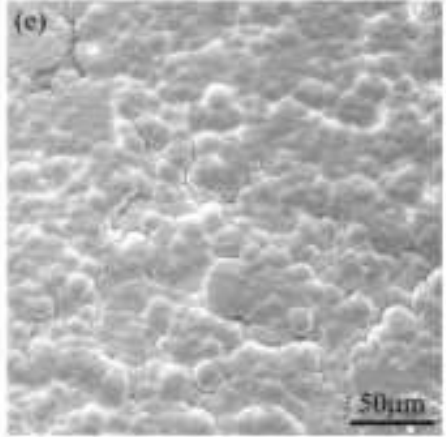

(e) $1000 \mathrm{~mm} / \mathrm{min}$

Fig. 9 Surface morphology of the coating center at different scanning speeds

After 10min of test, the section thickness of the coating center at different scanning speeds is shown in Fig. 10. The experimental results show that the coating thickness increases first and then decreases with the increase of scanning speed. The thickness growth rule is consistent with the simulation results, and the coating growth is uniform and the thickness is symmetric about the center. When the scanning speed is small (as shown in Fig. 10(a) and (c)), the coating surface is relatively smooth; when the scanning speed is large (as shown in 
Fig. 10(d) and (e)), the coating flatness is low. However, due to the limitation of processing efficiency, the thickness value is different from the simulation result, which is consistent with the processing efficiency predicted above. By comparing the center thickness of the coating in simulation and test, the machining efficiency is calculated to be $77.38 \%, 78.09 \%, 82.00 \%$, $80.16 \%, 76.26 \%$, respectively. Therefore, the overall processing efficiency is $78.78 \%$ on this test platform.
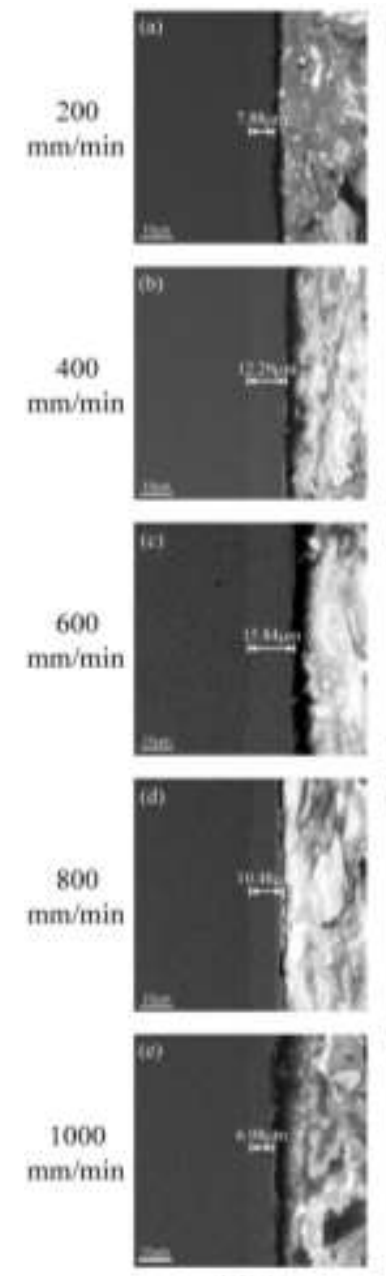

$-5 \mathrm{~mm}$
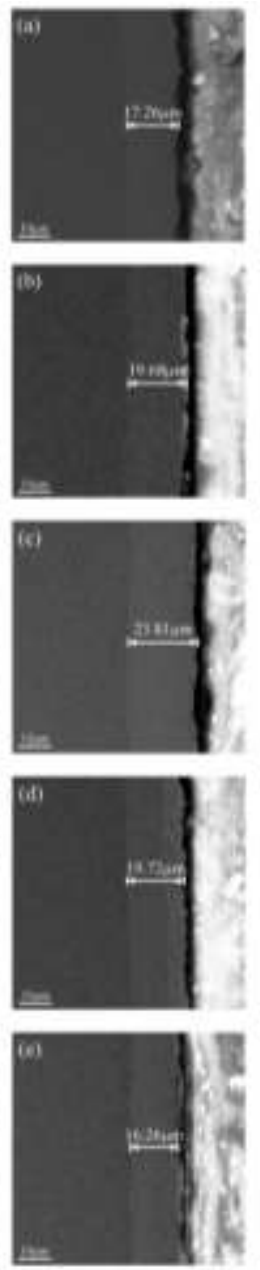

$-2 \mathrm{~mm}$
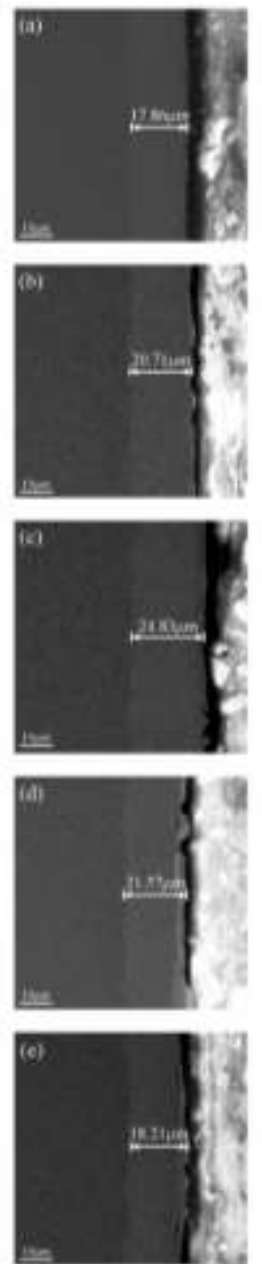

$0 \mathrm{~mm}$
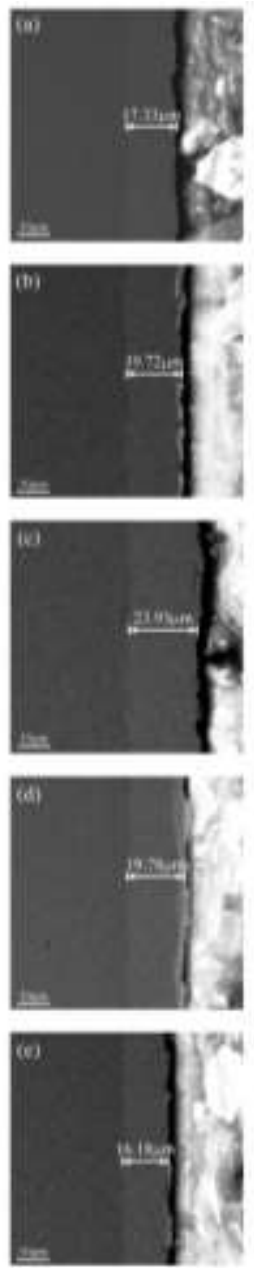

$2 \mathrm{~mm}$
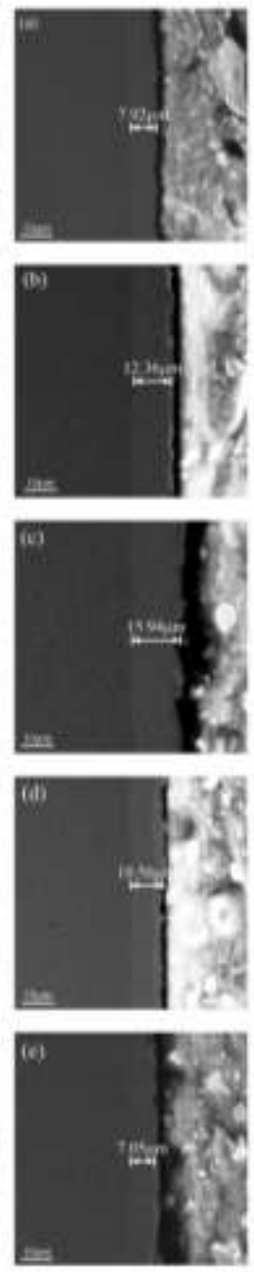

$5 \mathrm{~mm}$

Fig. 10 Section thickness of the coating at different scanning speeds

The Duramin-40 microhardness tester was used to test the microhardness of the samples. Five different points on each sample were selected to measure and then the average hardness was obtained. The microhardness at different scanning speeds was shown in Figure 11. Microhardness reflects the ability of materials to resist local plastic deformation. In this test, with the increase of scanning speed, the microhardness firstly increases and then decreases. When the scanning speed is $600 \mathrm{~mm} / \mathrm{min}$, the microhardness reaches the maximum value of $616.86 \mathrm{HV}$, and when the scanning speed is $200 \mathrm{~mm} / \mathrm{min}$, the microhardness is the lowest value of $529.09 \mathrm{HV}$. Combined with figure 9 shows that when scanning speed is low, the coating on the surface of the grain size is larger, leading to a lower microhardness, with the increase of scanning speed, coating grain size refinement, dense surface level off, the surface roughness is reduced, so the microhardness increases, when the scanning speed continues to increase, coating on the surface of fine scales, crack defects such as increased, and less hardness. Therefore, the main factors affecting the microhardness of the coating are grain size and surface quality of the coating. 


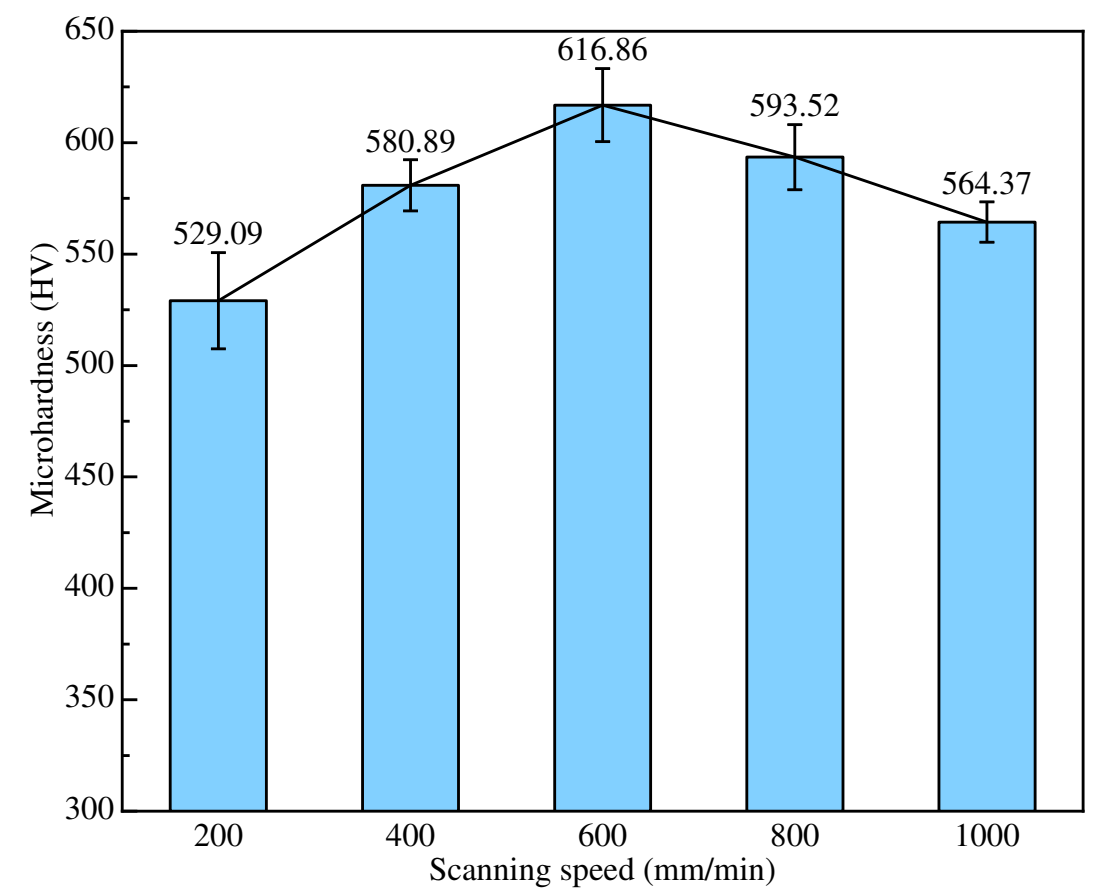

Fig. 11 Microhardness of the coating center at different scanning speeds

The CFT-I material surface comprehensive performance tester was used to carry out the friction and wear tests, and the sectional parameters (including section width, section height and section area) of the wear marks were measured by the LEXT OLS4100 laser confocal microscope. Figure 12 shows the threedimensional section diagram of the wear marks at different scanning speeds, and the specific parameter values are shown in Table 3. the sectional parameters are inversely proportional to the wear resistance. As can be seen from Table 3, with the increase of scanning speed, the sectional parameters decrease first and then increase, indicating that the wear resistance of the coating increases first and then decreases. When the scanning speed is $200 \mathrm{~mm} / \mathrm{min}$, the three cross section parameters of the coating are the highest, the cross section width is $498.61 \pm 9.17 \mu \mathrm{m}$, the cross section height is $16.86 \pm 0.82 \mu \mathrm{m}$, and the cross section area is $4904.97 \pm 57.57 \mu \mathrm{m}^{2}$. When the scanning speed is $600 \mathrm{~m} / \mathrm{min}$, the cross section parameters of the coating are obviously smaller than those at other scanning speeds, including the cross section width is $389.88 \pm 7.98 \mu \mathrm{m}$, the cross section height is $10.61 \pm 0.73 \mu \mathrm{m}$, and the cross section area is $2766.75 \pm 58.80 \mu \mathrm{m}^{2}$.The results show that the wear resistance of the coating is mainly affected by the hardness and grain size of the coating. The smaller the grain size, the higher the surface quality, the greater the microhardness, and the better the wear resistance of the coating. 


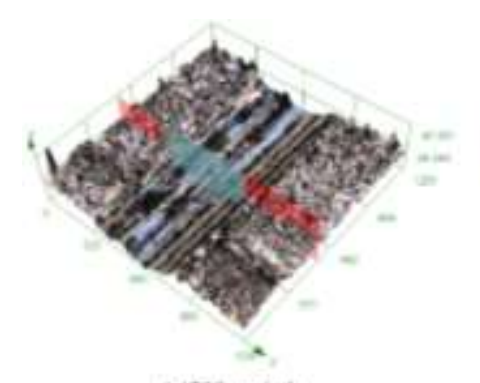

(a) 000 mminin

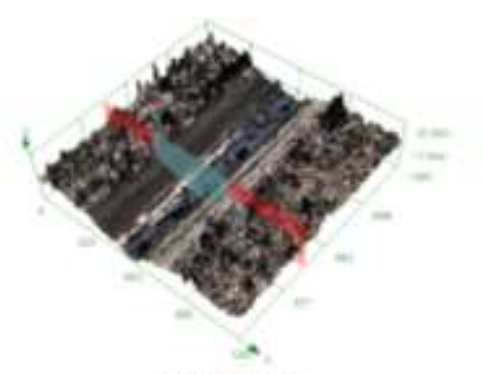

(b) 400 mminin

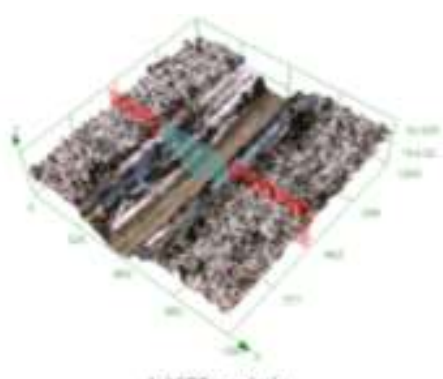

(c) 600 anminin
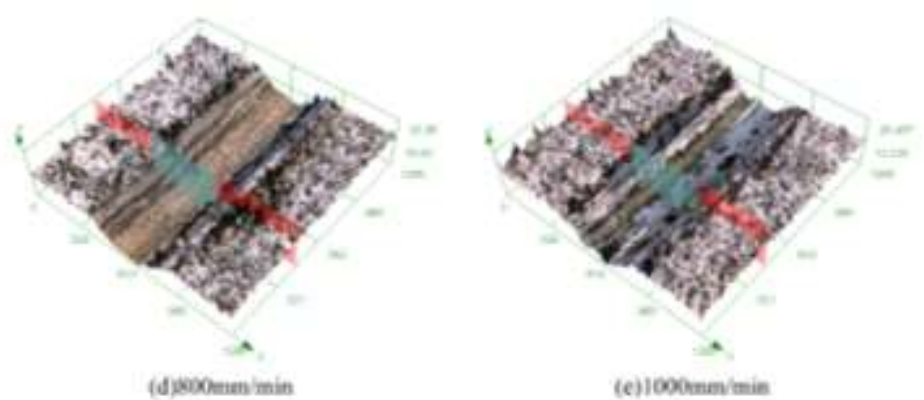

Fig. 12 Three-dimensional cross sections of wear marks at different scanning speeds

Table 3 sectional parameters of wear marks at different scanning speeds

\begin{tabular}{cccc}
\hline Scanning speed & Section width $(\mu \mathrm{m})$ & Height of section $(\mu \mathrm{m})$ & Section area $\left(\mu \mathrm{m}^{2}\right)$ \\
\hline $200 \mathrm{~mm} / \mathrm{min}$ & $498.61 \pm 9.17$ & $16.86 \pm 0.82$ & $4904.97 \pm 57.57$ \\
$400 \mathrm{~mm} / \mathrm{min}$ & $412.37 \pm 8.89$ & $14.07 \pm 0.85$ & $3754.15 \pm 63.88$ \\
$600 \mathrm{~mm} / \mathrm{min}$ & $389.88 \pm 7.98$ & $10.61 \pm 0.73$ & $2766.75 \pm 58.80$ \\
$800 \mathrm{~mm} / \mathrm{min}$ & $401.24 \pm 8.36$ & $11.65 \pm 0.97$ & $3356.02 \pm 61.05$ \\
$1000 \mathrm{~mm} / \mathrm{min}$ & $423.73 \pm 7.23$ & $12.57 \pm 0.74$ & $3645.60 \pm 51.74$ \\
\hline
\end{tabular}

Fig. 13 is the polarization curve of the nickel base coating prepared at different scanning speeds, and the values of the self-corrosion potential ( $\left.E_{\text {corr }}\right)$ and selfcorrosion current density ( $\left.\mathrm{I}_{\text {corr }}\right)$ of the nickel base coating at different scanning speeds are shown in Table 4. The results show that the scanning speed has a great influence on the self-corrosion potential and selfcorrosion current density of the nickel base coating. When the scanning speed increases from $200 \mathrm{~mm} / \mathrm{min}$ to $600 \mathrm{~mm} / \mathrm{min}$, the self-corrosion potential of the coating increases, and the self-corrosion current density decreases. As the scanning speed continues to increase, the self-etching potential of the coating decreases and the self-etching current density increases. When the scanning speed is $600 \mathrm{~mm} / \mathrm{min}$, the selfcorrosion potential of the coating is the maximum ($0.33 \mathrm{~V})$, and the self-corrosion current density is the minimum $\left(5.16 \mathrm{e}-7 \mathrm{~A} \cdot \mathrm{cm}^{2}\right)$, which indicates that the corrosion resistance of the coating is good, because the surface grains of the coating obtained at this scanning speed are fine and compact, the coating quality is good and the thickness is the maximum. When the scanning speed is $1000 \mathrm{~mm} / \mathrm{min}$, the self-corrosion potential of the coating is the smallest $(-0.77 \mathrm{~V})$, and the selfcorrosion current density is the largest $\left(1.04 \mathrm{E}-5 \mathrm{~A} \cdot \mathrm{cm}^{2}\right)$, indicating that the corrosion resistance of the coating is poor. This is because the surface of the coating appears fine chips, cracks, holes and other defects, and the surface quality of the coating is poor. This greatly reduces the corrosion resistance of the coating. When the scanning speed is $200 \mathrm{~mm} / \mathrm{min}$, the corrosion performance of the coating is poor according to the self-corrosion potential $(-0.65 \mathrm{~V})$ and self-corrosion current density $\left(1.36 \mathrm{E}-5 \mathrm{~A} \cdot \mathrm{cm}^{2}\right)$. This is because although the coating has no obvious surface defects at this time, the surface grain of the coating is large, and the microhardness and wear resistance of the coating are poor. This results in the coating being susceptible to 
erosion by corrosion products.

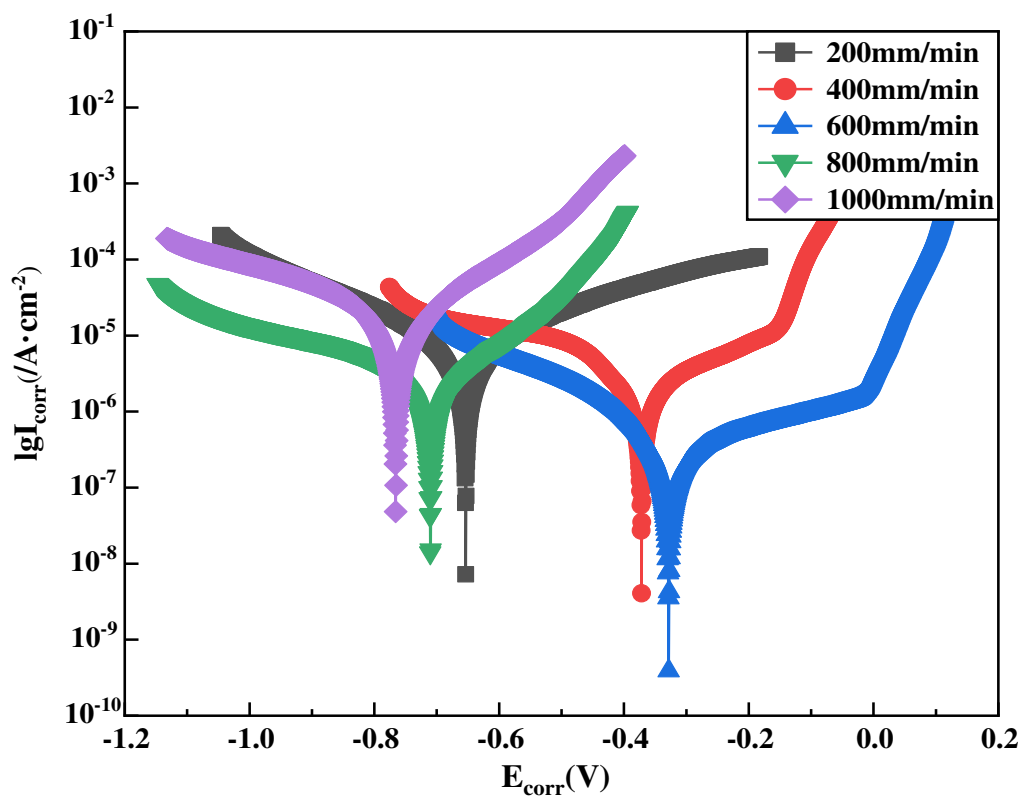

Fig. 13 Polarization curves of the coating at different scanning speeds

Table 4 Electrochemical corrosion parameters of coatings at different scanning speeds

\begin{tabular}{ccc}
\hline Scanning speed & Self-corrosion potential $(\mathrm{V})$ & Self-etching current density $\left(\mathrm{A} \cdot \mathrm{cm}^{2}\right)$ \\
\hline $200 \mathrm{~mm} / \mathrm{min}$ & -0.65 & $1.36 \mathrm{E}-5$ \\
$400 \mathrm{~mm} / \mathrm{min}$ & -0.37 & $7.99 \mathrm{E}-6$ \\
$600 \mathrm{~mm} / \mathrm{min}$ & -0.33 & $5.16 \mathrm{E}-7$ \\
$800 \mathrm{~mm} / \mathrm{min}$ & -0.71 & $1.58 \mathrm{E}-5$ \\
$1000 \mathrm{~mm} / \mathrm{min}$ & -0.77 & $3.04 \mathrm{E}-5$ \\
\hline
\end{tabular}

Fig. 14 shows the impedance spectrum diagram of the nickel-based coating at different scanning speeds. The capacitive arc radius in the figure indicates the impedance value of the coating. The larger the radius, the stronger the corrosion resistance of the coating. In the figure, RS represents the equivalent resistance of $\mathrm{NaCl}$ solution, $\mathrm{RP}$ represents the equivalent resistance of 45 steel matrix, CPE1 of the original constant phase Angle is related to the double-layer capacitance of the substrate, CPE2 is related to the double-layer capacitance of the coating reaction, and RT represents the equivalent resistance of the coating, which is an important parameter of the reaction coating resistance to electrolyte corrosion. With the increase of scanning speed, the impedance value of the coating first increases and then decreases. When the scanning speed is $600 \mathrm{~mm} / \mathrm{min}$, the impedance value of the coating is the largest, reaching $4660 \Omega$, which has the best corrosion protection effect on the workpiece. At $1000 \mathrm{~mm} / \mathrm{min}$, the impedance value of the coating is the smallest, which is $1882 \Omega$, showing the worst corrosion resistance. This is because there are obvious defects on the surface of the coating at this time, and the surface quality is very low, which leads to the insignificant corrosion protection effect of the coating. 


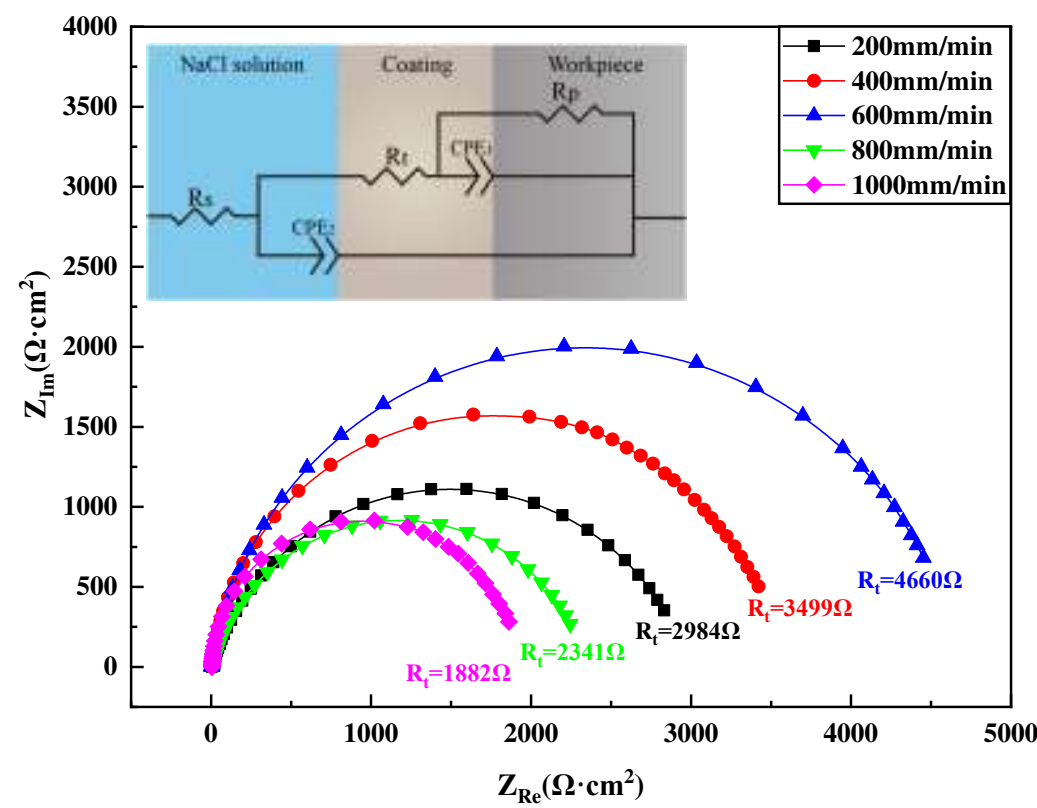

Fig. 14 Impedance spectrum diagram of nickel base coating at different scanning speeds

\section{Conclusion}

(1) Numerical results of spray electrodeposition with COMSOL software show that the coating thickness increases first and then decreases with the increase of scanning speed. When the scanning speed is $600 \mathrm{~mm} / \mathrm{min}$, the maximum coating thickness is $30.28 \mu \mathrm{m}$.

(2) SEM results show that when the scanning speed is $200 \mathrm{~mm} / \mathrm{min}$, the surface grain size of the coating prepared by jet electrodeposition is larger and the boundary is clear. With the increase of scanning speed, the grain size decreases. When it reaches $600 \mathrm{~mm} / \mathrm{min}$, the grain size of the coating surface is fine and the structure is compact. When it reaches 800 and $1000 \mathrm{~mm} / \mathrm{min}$, obvious cracks and other defects appear on the surface of the coating surface, and the surface quality is poor. The growth law of section thickness of coating prepared by jet electrodeposition is consistent with that of simulation, which verifies the accuracy of simulation.

(3) The microhardness and wear resistance tests show that the maximum microhardness of the coating is $616.86 \mathrm{HV}$, and the minimum cross section area of the wear mark is $2766.75 \pm 58.80 \mu \mathrm{m} 2$ when the coating is $600 \mathrm{~mm} / \mathrm{min}$. The wear resistance of the coating is the best. The grain size has a great influence on the microhardness and wear resistance. At $200 \mathrm{~mm} / \mathrm{min}$, the grain size is the largest, the microhardness of the coating is the lowest, which is $529.09 \mathrm{HV}$, and the wear resistance is the worst. The cross-section area of the coating is $4904.97 \pm 57.57 \mu \mathrm{m} 2$.

(4) Corrosion behavior analysis results show that the coating at $600 \mathrm{~mm} / \mathrm{min}$ has the highest self-corrosion potential, the lowest self-corrosion current density and the largest capacitance arc radius, showing the best corrosion resistance. At $1000 \mathrm{~mm} / \mathrm{min}$, the coating has the lowest self-corrosion potential, the highest selfcorrosion current density, and the smallest tolerance arc radius, showing the worst corrosion resistance, indicating that the surface quality of the coating has a great influence on the corrosion resistance of the coating.

Funding information: Financial support for this work was provided by Jiangsu Agricultural Science and Technology Innovation Fund (Grant number CX (20) 3085); Fundamental Research Funds for the Central Universities (Grant number KYXJ202002); Innovation and Development Project of Shihezi University(Grant number CXFZ202015).

Conflicts of interest: No potential conflict of interest was reported by the authors.

Availability of data and material: All data and material are true and valid, available.

Code availability: Not applicable

Ethics approval: Not applicable

Consent to participate: All authors agree to 
participate.

Consent for publication: All authors have read and agreed to the published version of the manuscript.

Authors' contributions: Conceptualization, Xiuqing $\mathrm{Fu}$ and $\mathrm{Jia} \mathrm{Li}$; methodology, Xiuqing Fu and Hongwen Zhang; software, Xiuqing Fu and Jia Li; validation, Jia $\mathrm{Li}$ and Jieyu Xian; formal analysis, Hongwen Zhang and Xiuqing $\mathrm{Fu}$; investigation, Xiuqing $\mathrm{Fu}$ and $\mathrm{Jia} \mathrm{Li}$;

\section{References}

[1] Ning D, Zhang A, Murtaza M, Wu H. (2019) Effect of surfactants on the electrodeposition of $\mathrm{Cu}-\mathrm{TiO} 2$ composite coatings prepared by jet electrodeposition. Journal of Alloys and Compounds,777:1245-1250. doi: https://doi.org/10.1016/j.jallcom.2018.11.077

[2] Krastev I, Dobrovolska T. (2013) Pattern formation during electrodeposition of alloys. Journal of Solid State Electrochemistry, 17:481-488. doi:

[3] He G, Lu S, Xu W, Ye P, Liu G, Wang H, Dai T. (2018) Stable superhydrophobic $\mathrm{Zn} / \mathrm{ZnO}$ surfaces fabricated via electrodeposition on tin substrate for self-cleaning behavior and switchable wettability. Journal of Alloys and Compounds, 747:772-782.

https://doi.org/10.1016/j.jallcom.2018.03.108

[4] Qiao G, Jing T, Wang N, Gao Y, Zhao X, Zhou J, Wang W. (2005) High-speed jet electrodeposition and microstructure of nanocrystalline Ni-Co alloys. Electrochimica Acta,51:85-92. doi: https://doi.org/10.1016/j.electacta.2005.03.050

[5] Jiang W, Shen L, Qiu M, Xu M, Tian Z. (2018) Microhardness, wear, and corrosion resistance of $\mathrm{Ni}-\mathrm{SiC}$ composite coating with magnetic-field-assisted jet electrodeposition. Materials Research Express,5:96407. doi: 10.1088/2053-1591/aad72c

[6] Cui W, Wang K, Xia F, Wang P. (2018) Simulation and characterization of $\mathrm{Ni}$-doped $\mathrm{SiC}$ nanocoatings prepared by jet electrodeposition. Ceramics International,44:55005505. doi: https://doi.org/10.1016/j.ceramint.2017.12.189

[7] Xia FF, Jia WC, Ma CY, Yang R, Wang Y, Potts M. (2018) Synthesis and characterization of Ni-doped TiN thin films deposited by jet electrodeposition. Applied Surface Science,434:228-233. doi: https://doi.org/10.1016/j.apsusc.2017.10.203

[8] TIAN Z, WANG D, WANG G, SHEN L, LIU Z, HUANG Y. (2010) Microstructure and properties of nanocrystalline resources, Xiuqing Fu and Jieyu Xian; data curation, Jia Li; writing original draft preparation, Xiuqing $\mathrm{Fu}$ and Jia Li; writing review and editing, Xiuqing Fu, Jia Li and Jieyu Xian; visualization, Hongwen Zhang and Jieyu Xian; supervision; project administration, Xiuqing $\mathrm{Fu}$ and Jia Li; funding acquisition, Xiuqing $\mathrm{Fu}$ and Jieyu Xian.

nickel coatings prepared by pulse jet electrodeposition. Transactions of Nonferrous Metals Society of China,20:1037-1042. doi: https://doi.org/10.1016/S10036326(09)60254-5

[9] Xia F, Jia W, Jiang M, Cui W, Wang J. (2017) Microstructure and corrosion properties of $\mathrm{Ni}-\mathrm{TiN}$ nanocoatings prepared by jet pulse electrodeposition. Ceramics International,43:14623-14628. doi: https://doi.org/10.1016/j.ceramint.2017.07.117

[10] Rajput MS, Pandey PM, Jha S. (2014) Fabrication of nanosized grain micro features using ultrasonic-assisted jet electrodeposition with pulsed current supply. Proceedings of the Institution of Mechanical Engineers, Part B: Journal of Engineering Manufacture,228:1338-1349. doi: $10.1177 / 0954405413520142$

[11] Jiang W, Shen L, Qiu M, Wang X, Fan M, Tian Z. (2018) Preparation of $\mathrm{Ni}-\mathrm{SiC}$ composite coatings by magnetic field-enhanced jet electrodeposition. Journal of Alloys and Compounds,762:115-124. doi: https://doi.org/10.1016/j.jallcom.2018.05.097

[12] Pérez T, Arenas LF, Villalobos-Lara D, Zhou N, Wang S, Walsh FC, Nava JL, et al. (2020) Simulations of fluid flow, mass transport and current distribution in a parallel plate flow cell during nickel electrodeposition. Journal of Electroanalytical Chemistry,873:114359. doi: https://doi.org/10.1016/j.jelechem.2020.114359

[13] Rajput MS, Pandey PM, Jha S. (2015) Modelling of high speed selective jet electrodeposition process. Journal of Manufacturing Processes, 17:98-107. doi: https://doi.org/10.1016/j.jmapro.2014.07.012

[14] Huang D, Shen L, Chen J, Zhu J. (2014) The Influence of Cathode Surface Velocity on Friction Aided Jet Electrodeposition. Transactions of the Indian Institute of Metals,67:351-357. doi:

[15] Cui W, Wang K, Wang K, Wang P. (2018) Effects of jet rate on microstructure, microhardness, and wear behavior 
of jet electrodeposited $\mathrm{Ni}-\mathrm{SiC}$ composites. Ceramics International,44:7214-7220.

https://doi.org/10.1016/j.ceramint.2018.01.169

[16] Shourije S, Bahrololoom ME. (2020) Comparison of effects of simulated electric field interference and presence of a barrier in the nickel electroplating process to experimental data. Transactions of the Institute of Metal Finishing,98:1-11. doi:

[17] Wang CY, Lin JC, Chang YC, Tseng YT, Ciou YJ, Hwang YR. (2019) Fabrication of Cu-Zn Alloy Micropillars by Potentiostatic Localized Electrochemical Deposition. Journal of The Electrochemical Society,166:E252-E262. doi:

[18] Zhou D, Ju H, Chen H. (1996) Catalytic oxidation of dopamine at a microdisk platinum electrode modified by electrodeposition of nickel hexacyanoferrate and Nafion ${ }^{\circledR}$. Journal of Electroanalytical Chemistry,408:219-223. doi: https://doi.org/10.1016/0022-0728(95)04522-8

[19] Liu X, Shen L, Qiu M, Tian Z, Wang Y, Zhao K. (2016) Jet electrodeposition of nanocrystalline nickel assisted by controllable friction. Surface and Coatings Technology,305:231-240. doi: https://doi.org/10.1016/j.surfcoat.2016.08.043

[20] Jiang M, Ma C, Xia F, Zhang Y. (2016) Application of artificial neural networks to predict the hardness of Ni-TiN nanocoatings fabricated by pulse electrodeposition. Surface and Coatings Technology,286:191-196. doi: https://doi.org/10.1016/j.surfcoat.2015.12.032

[21] Jiang W, Shen L, Xu M, Wang Z, Tian Z. (2019)
Mechanical properties and corrosion resistance of Ni-Co$\mathrm{SiC}$ composite coatings by magnetic field-induced jet electrodeposition. Journal of Alloys and Compounds, 791:847-855. doi: https://doi.org/10.1016/j.jallcom.2019.03.391

[22] Hassani S, Raeissi K, Azzi M, Li D, Golozar MA, Szpunar JA. (2009) Improving the corrosion and tribocorrosion resistance of $\mathrm{Ni}-\mathrm{Co}$ nanocrystalline coatings in $\mathrm{NaOH}$ solution. Corrosion Science,51:2371-2379. doi https://doi.org/10.1016/j.corsci.2009.06.026

[23] Sen R, Bhattacharya S, Das S, Das K. (2010) Effect of surfactant on the co-electrodeposition of the nano-sized ceria particle in the nickel matrix. Journal of Alloys and Compounds,489:650-658. doi: https://doi.org/10.1016/j.jallcom.2009.09.142

[24] Frías-Ferrer Á, Tudela I, Louisnard O, Sáez V, Esclapez MD, Díez-García MI, Bonete P, et al. (2011) Optimized design of an electrochemical filter-press reactor using CFD methods. Chemical Engineering Journal,169:270-281. doi: https://doi.org/10.1016/j.cej.2011.02.053

[25] Wu M, Liu J, He J, Chen X, Guo Z. (2020) Fabrication of surface microstructures by mask electrolyte jet machining. International Journal of Machine Tools and Manufacture, 148:103471 doi: https://doi.org/10.1016/j.ijmachtools.2019.103471

[26] Xia F, Zhao X, Jiang M, Ma C. (2019) Influence of nozzlefluid velocity on morphology and wear resistance of jet flow electrodeposited Ni-doped $\mathrm{SiC}$ composites. AIP Advances,9:65310. doi: 